\section{Anticoagulation for Chronic Non Valvular Atrial Fibrillation in the Elderly: A Review}

\author{
Nigel P Murray ${ }^{1,2 *}$ \\ ${ }^{1}$ Hospital de Carabineros de Chile, Nuñoa, Santiago, Chile \\ ${ }^{2}$ Department of Medicine, University Finis Terrae, Providencia, Santiago, \\ Chile
}

\begin{abstract}
The prevalence of atrial fibrillation increases with age, and as a result the risk of stroke and system embolism is increased when compared with younger patients. This is also matched in an increase in the hemorrhagic risk of using oral anticoagulation. For most patients' oral anticoagulation is the most effective treatment to reduce embolic risk however it is underused in the elderly for fear of hemorrhage. This article discusses the risk assessment tools for clinical decision making and pharmacological options for the prevention of stroke in the elderly and highlights several practical considerations to use of vitamin $K$ antagonists and newer non-vitamin $\mathrm{K}$ dependent oral anticoagulants in this growing population of patients.
\end{abstract}

Atrial Fibrillation (AF) is a major risk factor for disabling ischaemic stroke due to embolism from the left atrium. AF is the most frequent arrhymia in the elderly and its prevalence increases with age [1]. The true prevalence is difficult to determine as a substantial proportion of patients will be asymptomatic or have subclinical disease. However, two thirds of patients with AF will be at least 75 years old [2], and of the patients over 75 years $10 \%$ will have AF. The influence of $\mathrm{AF}$ on health outcomes increases with age in that $71 \%$ of strokes that occur in patients with AF are over 70 years [3] and that patient outcomes are worse in patients with AF than in those without $\mathrm{AF}[4]$.

Current guidelines recommend the use of anticoagulants to reduce the risk of embolic stroke in patients with $\mathrm{AF}[5,6]$. As with any pharmacological intervention there are risk and benefits with anticoagulant therapy. The benefit is the decrease in stroke at the

\footnotetext{
${ }^{*}$ Corresponding author: Nigel P Murray, Department of Medicine, University Finis Terrae, Providencia, Santiago, Chile, Tel: +56 274980507; E-mail: nigelpetermurray@gmail.com
}

Citation: Murray NP (2015) Anticoagulation for Chronic Non Valvular Atria Fibrillation in the Elderly: A Review. J Hematol Blood Transfus Disord 2: 003.

Received: March 30, 2015; Accepted: May 29, 2015; Published: June 26, 2015 expense of (the cost) hemorrhage and frequent blood testing in the case of Vitamin K Antagonists (VKA) and dietary restrictions.

There are simple clinical tools to assess the benefits and risks of anticoagulant therapy using easily available clinical data in the older patient.

To assess benefit due to stroke risk, the $\mathrm{CHADS}_{2}$ score (congestive heart failure, hypertension, age $>75$ years, diabetes mellitus and previous stroke or transient ischemic attack) is commonly used [7]. This tool which was developed in a population of elderly patients, gives one point for the presence of each risk factor and two points for a previous stroke or TIA. The risk of embolic stroke increases with each point of the $\mathrm{CHADS}_{2}$ tool, from $1.9 \%$ annual stroke risk with 0 points to $18.2 \%$ anual stroke risk in patients with a score of 6 points [8]. Most guidelines recomend the use of anticoagulation in patients with a $\mathrm{CHADS}_{2}$ score of 1 or greater. In a study of 773 patients older than 75 years with AF, $49 \%$ had congestive heart failure, $83 \%$ hypertension, $21 \%$ diabetes and $32 \%$ previous stroke or TIA [9]. Or in other words nearly all patients over 75 years meet the recomendations for anticoagulation.

To assess the risk for hemorrhage there are three prediction tools; firstly the HAS-BLED score [10], which includes hypertension; abnormal renal/liver function, stroke, bleeding history or predisposition, Labile International Normalized Ratio, elderly ( $>65$ years), drugs/alcohol concomitantly and has been incorporated into the European and Canadian guidelines on the management of patients with AF $[6,11]$. The HAS-BLED score is designed to estimate the 1 year risk of major bleeding (intracranial, hospitalization, hemoglobin decrease of $>2 \mathrm{gr} / \mathrm{dl}$ or need for transfusion) in patients older than 65 years. It is simple to use, and the trade-off in terms of the benefits and risks of oral anticoagulation demonstrates that in the majority of patients with AF, the risk of bleeding outweighs the potential benefit of anticoagulation if the HAS-BLED score excedes the CHADS2 $2_{2}$ score.

The $\mathrm{HEMOR}_{2}$ RHAGES score is more complex (hepatic or renal disease, ethanol abuse, malignancy, older age, reduced platelet count or function, re-bleeding, hypertension, anemias, genetic actors, excessive fall risk and stroke) needing laboratory tests or even genetic testing [12].

The ATRIA score uses clinical details of the patient, anemia, severe renal disease, age $\geq 75$ years, prior bleeding and hypertension to stratify patients into low, intermediate and high risk groups for hemorrhage [13]. Studies comparing the different risk prediction tools have shown that the HAS-BLED was superior to both the HEMOR $_{2}$ RHAGES and ATRIA tools [14,15].

The use of oral anticoagulants reduces the incidence of embolic stroke in patients with $\mathrm{AF}$, using the $\mathrm{CHADS}_{2}$ score the annual incidence of stroke can be predicted, the risk of bleeding from the HAS-BLED tool can likewise be predicted, benefit equals $\mathrm{CHADS}_{2}$ score minus HAS-BLED score.

However, if things were so simple, why is it that fewer than $60 \%$ of ideal candidates are anticoagulated [16-18]. $9 \%$ of people over 80 years 
have atrial fibrillation with five times the risk of a stroke than people over 80 years without atrial fibrillation. Regardless of the HAS-BLED score, when it is $\geq 3$ caution and efforts to correct reversible risk factors are advised, oral anticoagulants are recomended in all $\mathrm{CHADS}_{2}$ scores of $\geq 2$, with a Ia recomendation 1A [19]. However, it has been shown that estimates of bleeding risks by treating physicians are overstated, by as much as $18 \%$ [20] and as such under-usage is frequent.

One major consideration not included in either the $\mathrm{CHADS}_{2}$ or HAS-BLED scores is the evaluation of the elderly person as a whole and not a series of risk factors.

Anticoagulation is complex in elderly patients, the main randomly controlled clinical trials rarely include frail elderly patients, representing only $20 \%$ of patients studied and as such the guidelines do not provide recomendations for their management [21]. Frailty increases the risk of stroke but not of hemorrhage and has been reported to be associated with lower vitamin $\mathrm{K}$ antagonist usage [22]. In the absence of clear indications for this class of patients, areas that should be taken into account both before starting or discontinuing anticoagulation are; comorbidities, polypharmacotherapy, adherence, cognitive impairment, mobility and monitoring barriers, nutrional status and swallowing disorders, risk of falls and reduced life expectancy [23].

The risk of bleeding increases with age due to multiple factors, greater vascular fragility, less efficient haemostatic mechanisms and increased risk of pathologies with potential for bleeding. The risk of hemorrhages in the elderly doubles in patients with frequent falls, neuro-psychiatric diseases and previous stroke and triples in those over 75 years [24].

Falls are realtively common in the frail elderly, published data in the elderly $>65$ years showed that the mortality in patients hospitalized after a first fall was $6 \%$ in patients anticoagulated compared with $3.1 \%$ of patients without anticoagulation. Patients dying of a head injury constituted $31.6 \%$ of deaths within anticoagulated patients compared with $23.8 \%$ of those not recieving anticoagulation. Risk of eventual death with a head injury exceded the annual stroke risk in patients with a $\mathrm{CHADS}_{2}$-VASc score of 0-2 [25]. In the real world a prior history of falls/trauma is uncommon, reported to be approximately $1 \%$, these patients are likely to be older and have risks for stroke or thromboembolism, all cause mortality, major bleeding but not hemorrhagic stroke [26]. In comparison self reported activity by patients, classified as low, moderate and high was inversely associated with bleeding, the incidence of a major bleed was 3.5 times higher and non-major bleeds twice as high in patients reporting low activity as compared with the high activity group [27].

Cognitive impairment increases with age, studies using the mini-mental test, a questionaire comprising 30 questions that assess cognitive function [28], reported that cognitive dysfunction was common, the score of the mini-mental test correlated with poorer anticoagulation control and that patients with low scores had an increased risk of vascular events and bleeding. In patients with cognitive dysfunction improved control of anticoagulation reduced this risk of vascular and bleeding events [29]. The impact of cognitive impairment is a major public health challenge and is accentuated in patients taking oral anticoagulants that require care in taking the medication as prescribed and being aware of drug and dietary interactions. Atrial fibrillation is independently associated with cognitive dysfunction, with increased thrombin generation and fibrin turnover, with higher $\mathrm{D}$-dimer, prothrombin fragment $1+2$ and thrombin-anti-thrombin comlexes were reported in patients with dementia and FA when compared with patients with only FA [30]. However, it has been reported that anticoagulation was no better than aspirin in protecting against cognitive decline as measured by the mini-mental score, other than that provided by preventing clinical stroke [31]. However, with proper instruction to the patient or carer, mild to moderate cognitive dysfunction does not delay the time required to achieve therapeutic anticoagulation nor decreased anticoagulation stability in terms of number of clinic visits compared with patients with normal cognitive function [32]. However with decreasing cognitive function the frequency of prescibing anticoagulation decreases significatively [33].

Novel non-vitamin $\mathrm{K}$ antagonists have been introduced in the last few years which do not require monitoring, do not have dietary interactions and have fewer drug interactions. Two direct thrombin inhibitors, ximelagatran and dabigatran and two factor Xa inhibitors apixaban and rivaroxaban have been evaluated in large phase III clinical trials. However ximelagatran was removed from the market in 2006. They have been approved for clinical use and have been shown to beat least non-inferior to dose adjusted warfarin for stroke prevention.

Dabigatran in a dose of $150 \mathrm{mg}$ and 110 twice daily in the randomized evaluation of long-term anticoagulant therapy (RE-LY Trial) was associated with a lower risk of hemorrhage in patients $<75$ years, but not in those over 75 years. The risk of major hemorrhage and extracranial hemorrhage rose more steeply with age than with warfarin. In a dose of $150 \mathrm{mg}$ twice daily there was an increased risk of major gastrointestinal bleeding when compared with warfarin, however the risk of intracranial hemorrhage was lower with both doses of dabigatran [34]. Adherence to treatment of more than $80 \%$ in $76 \%$ of patients with $16 \%$ discontinuing treatment due to heartburn [35]. In terms of reduced risk of stroke or systemic embolism, the dose of $150 \mathrm{mg}$ twice daily was superior to warfarin, the $110 \mathrm{mg}$ twice daily dosage being non-inferior. In the subsequent RELY-ABLE trial, comparing the $150 \mathrm{mg}$ versus $110 \mathrm{mg}$ dosis scheme, there was a higher rate of major bleeding with the $150 \mathrm{mg}$ dosis but with similar rates of stroke and death [36].

Rivaroxaban is less dependenton renal excretion than dabigatran or apixaban, and has a once daily dose. The ROCKET-AF study showed rivaroxaban to be non-inferior to dose adjusted warfarin [37], with a lower risk of intracerebral and fatal hemorrhages, however there was an increased risk of non-major clinically relevant bleeding in patients over 75 years in comparison with warfarin [38]. Patients with intracranial hemorrhage while on treatment with rivaroxaban had smaller hematomas and lower modified Rankin Scale at discharge when compared to warfarin, although multiple cerebral microbleeds were more common with rivaroxaban than with warfarin. Death rates were higher in patients taking warfarin [39]. In a secondary analysis of the ROCKET AF trial, rivaroxaban was as effective and as safe as adjusted dose warfarin in elderly as compared with younger patients, but the net clinical benefit was significantly higher in older patients due to the prevention of ishemic stroke [40].

Apixaban was compared to warfarin in the ARISTOTLE trial (Apixaban for Reduction of Stroke and Other Thromboembolic Events) in atrial fibrillation [41], there was a 50\% dose reduction in patients with 2 of the following 3 criteria; a serum creatinine of $>1.5 \mathrm{mg} / \mathrm{dl}$, aged over 80 years or a body weight of less than $60 \mathrm{~kg}$. Apixaban was shown to be more effective than warfarin but with 
significant lower major hemorrhage rate, even those with moderate renal failure showed a $50 \%$ rate reduction in hemorrhages when compared to warfarin. The relative risk of bleed reduction was higher in patiets with higher bleeding risks [42]. In patients considered unsuitable for warfarin, the AVERROES trial showed apixaban to be superior to aspirin in preventing stroke or systemic embolism in patients with FA, including those over 75 years with no significant increased risk of bleeding [43].

Of note is the renal metabolism of the newer anticoagulants, renal function gradually declines with age, over $50 \%$ of elderly patients with AF have an estimated glomular filtration rate of $<60 \mathrm{ml} / \mathrm{min}$, however it should be emphasized that chronic kidney disease increases the risk of stroke in these patients and thus they should receive anticoagulation. With the differing options of anticoagulants there is no reason why the best choice to fit the clinical parameters is not made. When the creatine clearence decreases to $<30 \mathrm{ml} / \mathrm{min}$ the risk for major hemorhage increases and newer anticoagulants are not recommended [44].

There are no head to head studies comparing the new non vitamin $\mathrm{K}$ anticoagulants but all reduce the relative risk of ishemic stroke by by approximately $30 \%$ and with a reduction in significant bleeds. They are easier to use in that they do not require blood monitoring and there are at present less interactions with commonly used medicines in the elderly nor dietary restrictions.

However, although clinical tools are available to predict the risk of stroke from $\mathrm{AF}$ and the bleeding risk, none consider the functional capacity of the elderly person, whether the person is bed ridden, has little functional capacity in terms of basic daily living activities, severe cognitive deterioration, social support in who supervises the medicines. The short half life of the new non vitamin $\mathrm{K}$ anticoagulants, especially when are twice daily means that forgetting to take the tablets is more important and leave the patient without anticoagulant protection. Bellelli et al., [45] argue that all geriatric patients with AF should be considered for anticoagulation but depending on their functional assessment whether they should receive it. Mortality is greater in patients with falls and/or dementia [46].

\section{In summary}

There are no doubts that people with AF should receive anticoagulation and not aspirin, which is not effective and has a risk of hemorrhage. With the new anticoagulants there is a choice of agents to best suit the patient, however, there is no consensus on at what functional level should the older patient not recieve anticoagulation. This is the probable reason why many elderly patients do not receive anticoagulation as recommended or are treated with ineffective aspirin.

\section{References}

1. Rich MW (2009) Epidemiology of atrial fibrillation. J Interv Card Electrophysio 25: 3-8.

2. Hanon O, Assayag P, Belmin J, Collet JP, Emeriau JP, et al. (2013) Expert concensus of the French Society of Geriatrics and Gerontology and the French Socierty of Cardiology on the management of atrial fibillriation in elderly people. Arch Cardiovasc Dis 106: 303-323

3. Wolf PA, Abbott RD, Kannel WB (1991) Atrial fibrillation as an independent risk factor for stroke: the Framingham Study. Stroke 22: 983-988.

4. Tu H, Campbell BC, Christiansen S, Collins M, De Silva DA, et al. (2010) Pathophysiological determinants of worse stroke outcome in atrial fibrillation. Cerebrovasc Dis 30: 389-395.
5. Anderson JL, Halperin JL, Albert NM, Bozkurt B, Brindis RG, et al. (2013) Management of patients with atrial fibrillation (compilation of 2006 ACCF/ AHA/ESC and 2011 ACCF/AHA/HRS recomendations): a report of the American College of Cardiology/American Heart Association Task Force on Practice Guidelines. J Am Coll Cardiol 61: 1935-1944.

6. European Heart Rhythm Association, European Association for Cardio-Thoracic Surgery, Camm AJ, Kirchhof P, Lip GY, et al. (2010) Guidelines for the management of atril fibrillation: the Task Force for the Management of Atrial Fibrillation of the European Society of Cardiology (ESC). Eur Heart $J$ 31: $2369-2429$.

7. Gage BF, Waterman AD, Shannon W, Boechler M, Rich MW, et al. (2001) Validation of clinical classification schemes for predicting stroke: results from the National Registry of Atrila Fibrillation. JAMA 285: 2864-2870.

8. Pearce LA, Hart RG, Halperin JL (2000) Assessment of three schemes for stratifying stroke risk in patients with non valuvular atrial fibrillation. Am J Med 109: 45-51.

9. Maes F, Dalleur O, Henrard S, Wouters D, Scavée C, et al. (2014) Risk scores and geriatric profile: can they really help us in anticoagulation decision making among older patients suffering from atrial fibrillation? Clin Interv Aging 9: 1091-1099.

10. Pisters R, Lane DA, Nieuwlaat R, de Vos CB, Crijns HJ, et al. (2010) A novel user friendly score (HAS-BLED) to assess 1 year risk of major bleeding in patients with atrial fibrillation: the Euro Heart Survey. Chest 138: 1093-1100.

11. Cairns JA, Connolly S, McMurthy S, Stephenson M, Talajic M, et al. (2007) Canadian Cardiovascular Society atrial fibrillation guidelines 2010: prevention of stroke and systemic thromboembolism in atrial fibrillation and flutter. Canad J Cardiol 27: 74-90.

12. Gage BF, Yan Y, Milligan PE, Waterman AD, Culverhouse R, et al. (2006) Clinical classification schemes for predicting hemorrhage: results from the National Registry of Atrila Fibrillation (NRAF). Am Heart J 151: 713-719.

13. Fang MC, Go AS, Chang YC, Borowsky LH, Pomernacki NK, et al. (2011) A new risk scheme to predict warfarin associated hemorrhage: The ATRIA (Anticoagulation and Risk Factors in Atrial Fibrillation) study. J Am Coll Cardio 58: 395-401.

14. Roldán V, Marin F, Fernández $\mathrm{H}$, Manzano-Fernandez $\mathrm{S}$, Gallego $\mathrm{P}$, et al. (2013) Predictive value of the HAS-BLED and ATRIA bleeding scores forthe risk of serious bleeding in a "real-world" population with AF recveiving anticoagulant therapy. Chest 143: 179-184.

15. Apostolakis S, Lane DA, Guo Y, Buller H, Lip GY (2012) Performance of the HEMORR(2)HAGES, ATRIA and HAS-BLED bleeding risk-prediction scores in patients with atrial fibrillation undergoing anticoagulation: the AMADEUS (evaluating the use of SR34006 compared to warfarin or acenocoumarol in patients with atrial fibrillation) study. J Am Coll Cardiol 60: 861-867.

16. Bungard TJ, Ghali WA, Teo KK, McAlister FA, Tsuyuki RT (2000) Why do patients with atrial fibrillation not recieve warfarin? Arch Intern Med 160: 41-46.

17. Fang MC, Stafford RS, Ruskin JN, Singer DE (2004) National Trends in antiarrthymic and antithrombotic medication use in atrial fibrillation. Arch Intern Med 164: 55-60.

18. Ogilvie IM, Newton N, Welner SA, Cowell W, Lip GY (2010) Underuse of oral anticoagulants in atrial fibrillation: a systemic review. Am J Med 123: 638-645.

19. Nantsupawat T, Ngent K, Phrommintikul A (2013) Atrial fibrillation in the elderly. Drugs \& Aging 30: 593-601.

20. Berger AS, Dunn AS, Kelly AS (2014) A standardized bleeding risk score aligns anticoagulation choices with current evidence. Crit Pathw Cardiol 13: 109-113.

21. Chatap G, Giraud K, Vincent JP (2002) Atrial fibrillation in the elderly: facts and management. Drugs Aging 19: 819-846.

22. Sánchez-Barba B, Navarrete-Reyes AP, Avila-Funes JA (2013) Are geriatric syndromes associated with reluctance to initiate oral anticoagulation therapy in elderly adults with nonvalvular atrial fibrillation? J Am Geriatr Soc 61: 2236-2237. 
23. Granziera S, Cohen AT, Nante G, Manzato E, Sergi G (2015) Thromboembolic prevention in frail elderly patients with atrial fibrillation: A practical algorithm. J Am Med Dir Assoc 16: 358-364.

24. Stroke Prevention in Atrial Fibrillation Investigators (1995) Risk factors for thromboembolism during aspirin therapy in patients with atrial fibrillation: The stroke prevention in atrial fibrillation study. J Stroke Cerebrovasc Disease 5 : 147-157.

25. Inui TS, Parina R, Chang DC, Inui TS, Coimbra R (2014) Mortality after ground-level fall in the elderly patient taking oral anticoagulation for atrial fibrillation/flutter: a long term analysis of risk versus benefit. J Tauma Acute Care Surg 76: 642-649.

26. Banerjee A, Clementy N, Haguenoer K, Fauchier L, Lip GY (2014) Prior his tory of falls and risk of outcomes in atrial fibrillation: the Loire Valley Atrial Fibrillation Project. Am J Med 127: 972-978.

27. Frey PM, Méan M, Limacher A, Jaeger K, Beer HJ, et al. (2015) Physical activity and risk of bleeding in elderly patietns taking anticoagulants. J Thromb Haemost 13: 197-205.

28. Folstein M, Folstein S, McHugh P (1975) Mini mental state: A practical method for grading the cognitive status of patients for the clinician. J Psychiatr Res 12: 189-198.

29. Flaker GC, Pogue J, Yusuf S, Pfieffer MA, Goldhaber SZ, et al. (2010) Cognitive function and anticoagulation control in patients with atrial fibrillation. Cir Cardiovasc Qual Outcomes 3: 277-283.

30. Barber M, Tait RC, Scott J, Rumley A, Lowe GD, et al. (2004) Dementia in subjects with atrial fibrillation: hemostatic function and the role of anticoagulation. J Thromb Haemostat 2: 1873-1878.

31. Mavaddat N, Roalfe A, Fletcher K, Lip GY, Hobbs FD, et al. (2014) Warfarin versus aspirin for prevention of cognitive decline in atrial fibrillation: randomized controlled trial (Birmingham Atrial Fibrillation Treatment of the Aged Study). Stroke 45: 1381-1386.

32. Khreizat HS, Whittaker P, Curtis KD, Turlo G, Garwood CL (2012) The effect of cognitive impairment in the elderly on the initial and long-term stability of warfarin therapy. Drugs Aging 29: 307-317.

33. Gorzelak P, Zyzak S, Krewko Ł, Mozdzan M, Broncel M (2014) [Frequency of use of oral vitamin $\mathrm{K}$ antagonists in patients with atrial fibrillation and cognitive function disturbances]. Pol Merkur Lekarski 36: 302-306.

34. Connolly SJ, Ezekowitz MD, Yusuf S, Eikelboom J, Oldgren J, et al. (2009) Dabigatran versus warfarin in patients with atrial fibrillation. $\mathrm{N}$ Eng $\mathrm{J}$ Med 361: 1139-1151.
35. Verdecchia P, Molini G, Bartolini C, Filippo VD, Valecchi F, et al. (2014) Safety of dabigatran in an elderly population: single centre experience in Italy. Curr Drug Saf 10: 165-169.

36. Connolly SJ, Wallentin L, Ezekowitz MD, Eikelboom J, Oldgren J, et al. (2013) The long term multicenter observational study of dabigatran treatment in patients with atrial fibrillation (RELY-ABLE) study. Circulation 128: 237-243.

37. Patel MR, Mahaffey KW, Garg J, Pan G, Singer DE, et al. (2011) Rivaroxaban versus warfarin in nonvalvular atrial fibrillation. N Eng J Med 365: 883-889.

38. Halperin JL, Wojdyla D, Piccini JP, Lokhnygina Y, Patel MR, et al. (2012) Effiacacy and Safety of Rivaroxiban Compared with Warfarin among Elderly Patients with Nonvalvular AF in the ROCKET-AF Trial. Stroke 43: 148.

39. Hagii J, Tomita H, Metoki N, Saito S, Shiroto H, et al. (2014) Characterisitics of intracerebral hemorrhage during rivaroxaban treatment: comparison with those during warfarin. Stroke 45: 2805-2807.

40. Halperin JL, Hankey GJ, Wojdyla DM, Piccini JP, Lokhnygina Y, et al. (2014) Efficacy and safety of rivaroxaban compared with warfarin among elderly patients with non-valvular atrial fibrillation in the Rivaroxaban once daily, oral, direct Factor $\mathrm{Xa}$ inhibition compared with vitamin $\mathrm{K}$ antagonism for prevention of stroke and embolism trial in atrial fibrillation (ROCKET AF). Circulation 130: 138-146.

41. Granger CB, Alexander JH, McMurray JJ, Lopes RD, Hvlek EM, et al. (2011) Apixaban versus warfarin in patients with atrial fibrillation. $N$ Eng J Med 365: 981-992.

42. Lopes RD, Al-Khatib SM, Wallentin L, Yang, Ansell J, et al. (2012) Efficacy and safety of apixaban compared with warfarin according to patient risk of stroke and bleeding in atrial fibrillation: a secondary analysis of a randomised controlled trial. Lancet 380: 1749-1758.

43. Coppens M, Synhorst D, Elkelboom JW, Yusuf S, Shestakovska O, et al. (2014) Efficacy and safety of apixaban compared with aspirin in patients who previously tried but failed treatment with vitamin $\mathrm{K}$ antagonists: results from the AVERROES trial. Eur Heart J 35: 1856-1863.

44. Ng KH, Hart RG, Eikelboom JW (2013) Anticoagulation in Patients aged $\geq 75$ years with Atrial Fibrillation: Role of Novel Oral Anticvoagulants. Cardio Ther 2: 134-149.

45. Bellelli G, Bianchettia A, Tabucci M (2000) Anticoagulation to prevent stroke in atrial fibrillation. Comprehnesive geriatric evaluation should be routine before treatment is started. BMJ 321: 1157.

46. Jacobs LG, Billett HH, Freeman K, Dinglas C, Jumaquio L (2009) Anticoagulation for stroke prevention in elderly patients with atrial fibrillation, including those with falls and/or early stage dementia: a single center, retrospective, observational study. Am J Geriatr Pharmacother 7: 159-166. 